\title{
Model Struktural Faktor-Faktor Berpengaruh Terhadap Kinerja Badan Usaha Milik Desa di Kabupaten Jembrana, Bali
}

\author{
G K Gandhiadi \\ Prodi Matematika FMIPA Universitas Udayana \\ e-mail: gandhiadi@unud.ac.id \\ I Putu Eka N Kencana \\ Prodi Matematika FMIPA Universitas Udayana \\ e-mail: i.p.enk@unud.ac.id
}

\begin{abstract}
One of the efforts to develop the rural economy is the establishment of economic institutions such as Village-Owned Enterprises (BUMDes) which are supported by the role of the local government and are based on the wishes of the village community. This BUMDes is expected to be able to increase market demand based on proper management of the existing village potential. Through cooperative behavior (social capital), synergy and a good entrepreneurial orientation in BUMDes managers and the positive role of the government it is hoped that there will be an increase in BUMDes business performance in Jembrana Regency. The purpose of this study is to comprehensively analyze the role of government and social capital of business managers through entrepreneurial orientation towards BUMDes business performance in Jembrana Regency. The basis of multivariate analysis used is Structural Equation Modeling (SEM). Through a research sample of 90 respondents from BUMDes managers in Jembrana Regency, the results are obtained: (1) social capital and the role of government directly have a positive but not significant effect on business performance, while entrepreneurial orientation has a positive and significant effect on business performance, and (2) social capital and the role of the government in a total positive and significant effect and require full mediation (full mediation) through entrepreneurial orientation to the business performance of BUMDes in Jembrana Regency, Bali.
\end{abstract}

Keywords: Social Capital, Entrepreneurship Orientation, Business Performance of BUMDes, Government's Role

Abstrak: Upaya pengembangan ekonomi pedesaan sudah sejak lama dijalankan oleh pemerintah melalui berbagai program, namun upaya itu belum membuahkan hasil yang memuaskan. Salah satu ide yang ditawarkan adalah pendirian lembaga ekonomi seperti Badan Usaha Milik Desa (BUMDes) yang didukung peran pemerintah daerah dan didasarkan pada keinginan masyarakat desa. BUMDes ini diharapkan mampu meningkatkan permintaan pasar berdasarkan pengelolaan yang tepat atas potensi desa yang ada. Melalui perilaku kerja sama (modal sosial), sinergitas dan orientasi kewirausahaan yang baik pada pengelola BUMDes serta adanya peran pemerintah yang positif diharapkan ada peningkatan kinerja usaha 
BUMDes di Kabupaten Jembrana. Tujuan penelitian ini menganalisis secara komprehensif peran pemerintah dan modal sosial pengelola usaha melalui orientasi kewirausahaan terhadap kinerja usaha BUMDes di Kabupaten Jembrana. Salah satu dasar analisis multivariate yang melibatkan variabel-variabel sosial (variable laten) adalah Pemodelan Persamaan Struktural (SEM : Structural Equation Modeling). Melalui sampel penelitian sebanyak 90 responden dari pengelola BUMDes di Kabupaten Jembrana, diperoleh hasil sebagai berikut; (1) modal sosial dan peran pemerintah secara langsung berpengaruh positif tetapi tidak signifikan terhadap kinerja usaha, sedangkan orientasi kewirausahaan berpengaruh positif dan signifikan terhadap kinerja usaha, dan (2) modal sosial dan peran pemerintah secara total berpengaruh positif dan signifikan serta memerlukan mediasi penuh (full mediation) melalui orientasi kewirausahaan terhadap kinerja usaha BUMDes di Kabupaten Jembrana, Bali.

Kata kunci: Modal Sosial, Orientasi Kewirausahaan, Kinerja Usaha BUMDes, Peran Pemerintah

\section{Pendahuluan}

Pembentukan Badan Usaha Milik Desa (BUMDes) sebagai lokomotif pembangunan di desa merupakan adalah peran pemerintah dan masyarakat desa berdasarkan prinsip koperasi, partisipatif, dan emansipatoris masyarakat desa. Oleh karena itu, kinerja bisnis BUMDes akan sangat dipengaruhi oleh kapasitas modal sosial dan budaya manajer wirausaha di desa yang bersangkutan dan daripada peran pemerintah dalam pembangunan ekonomi pedesaan. Melalui perilaku kooperatif, sinergi dan orientasi kewirausahaan yang tinggi untuk manajemen BUMDes serta peran pemerintah yang positif, diharapkan akan ada peningkatan kinerja bisnis BUMDes. Modal sosial berfungsi untuk mengatasi berbagai macam hambatan kolektif dalam bidang bisnis, termasuk orientasi kewirausahaan (Fukuyama, 200). Modal sosial dipandang sebagai kapasitas seseorang untuk membangun jaringan berdasarkan norma yang berlaku dan kepercayaan pada orang lain (Gandhiadfi, dkk, 2017). Premis dasar dari objek penelitian ini adalah peran pemerintah dan modal sosial diharapkan mampu meningkatkan orientasi kewirausahaan sehingga mulut dapat meningkatkan kinerja bisnis BUMDes di Kabupaten Jembrana Bali. Penekanan dalam bidang matematika pada objek penelitian ini adalah untuk menguji model atau hubungan struktural menggunakan SEM (Structural Equation Modeling) (Hair, et al, 2017).

Penelitian ini secara khusus bertujuan untuk menguji pemodelan persamaan struktural atau hubungan yang menggambarkan peran pemerintah dan modal sosial melalui orientasi kewirausahaan kewirausahaan dalam meningkatkan kinerja bisnis BUMDes di Kabupaten Jembrana. 
Hasil penelitian ini diharapkan dapat memberikan kontribusi kepada para pemangku kepentingan dalam merumuskan strategi untuk pengembangan ekonomi pedesaan melalui BUMDes di Kabupaten Jembrana Bali.

\section{Metode Penelitian}

Data penelitian diambil di BUMDes di semua desa di Kabupaten Jembrana Bali, ada 37 BUMD aktif pada tahun 2019. Jumlah sampel yang dipilih adalah 2 atau 3 manajer (pelaku usaha) dari masing-masing BUMDes aktif (sekitar 90 responden).

Menggunakan indikator untuk variabel laten modal sosial, orientasi kewirausahaan dan kinerja bisnis hampir sama dengan indikator dalam penelitian Gandhiadi, dkk. (2017). Sedangkan indikator untuk peran pemerintah merujuk pada Diva dalam Taranggana GP (2017). Kemudian model penelitian dirancang menggunakan indikator-indikator ini seperti pada Gambar 1.

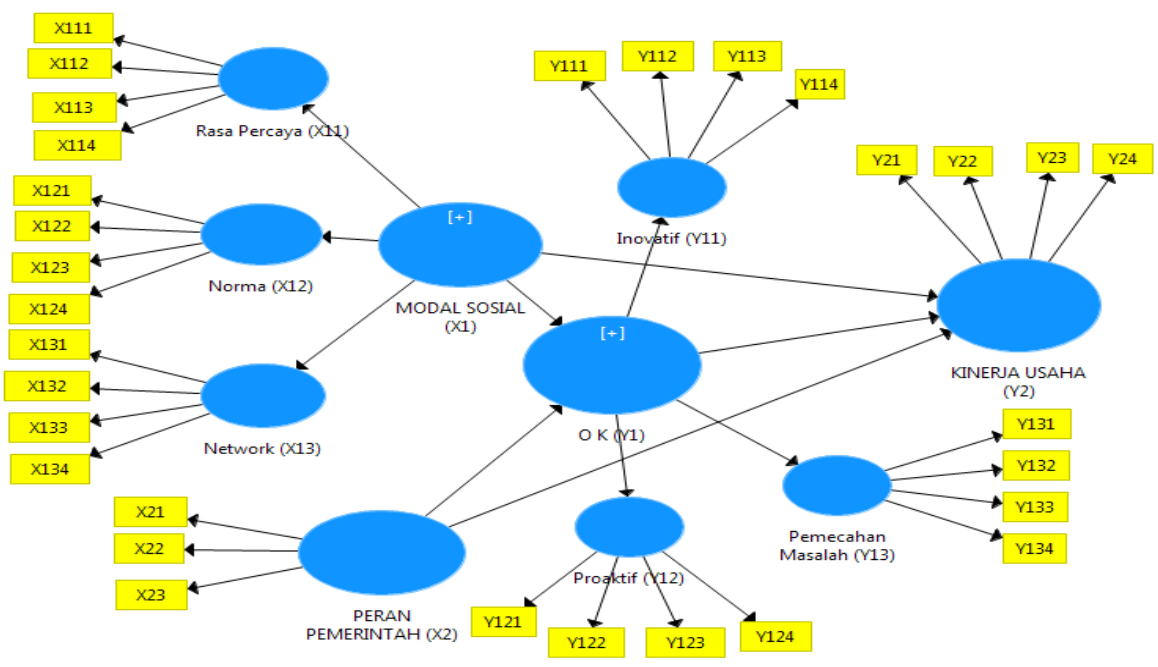

Gambar 1. Rancangan Penelitian

Uji instrumen penelitian (indikator) menggunakan uji validitas korelasi Product Moment dan uji reliabilitas teknik Cronbach Alpha $(\alpha)$ pada 30 data kuesioner awal untuk menguji tingkat kelayakan instrumen penelitian dari kuesioner yang digunakan (Hamed Taherdoost. 2016). Analisis data kemudian menggunakan langkah-langkah analisis menurut SEM-PLS (Hair, et al, 2017), dengan bantuan perangkat lunak Smart PLS 3.0 pada desain model penelitian.

Variabel laten serta indikator yang digunakan untuk menjelaskan variabel yang digunakan dalam model rancangan (model persamaan struktural) dalam penelitian ini, disajikan pada Tabel 1 berikut. 
Tabel 1. Variabel Laten, Indikator (Item Pertanyaan)

\begin{tabular}{|c|c|c|}
\hline $\begin{array}{r}\text { Variabel Laten } \\
\text { Orde Dua }\end{array}$ & $\begin{array}{l}\text { Variabel Laten } \\
\text { Orde Satu }\end{array}$ & Indikator (Item Pertanyaan) \\
\hline \multirow[t]{4}{*}{$\begin{array}{l}\text { Modal Sosial } \\
\text { (X1), } \\
{[6],[2]}\end{array}$} & $\begin{array}{r}\text { Rasa Percaya } \\
\text { (X11) }\end{array}$ & $\begin{array}{l}\text { X111: Sebagian besar orang peduli } \\
\text { X112: Kepercayaan terhadap tokoh agama } \\
\text { X113: Rasa saling percaya terhadap karyawan } \\
\text { X114: Kepercayaan terhadap teman bisnis lain }\end{array}$ \\
\hline & Norma (X12) & $\begin{array}{l}\text { X121: Keharmonisan sesuai Tri Hitta Karana } \\
\text { X122: Kepatuhan terhadap aturan yang ada } \\
\text { X123: Kemudahan mencari bantuan modal } \\
\text { X124: Kemudahan memperoleh bantuan pem- } \\
\text { binaan manajemen }\end{array}$ \\
\hline & $\begin{array}{r}\text { Jaringan Kerja } \\
\text { (X13) }\end{array}$ & $\begin{array}{l}\text { X131: Kepadatan jaringan kerja } \\
\text { X132: Kerjasama dengan karyawan (bonding) } \\
\text { X133: Kerjasama dg sesama pengelola BUMDes } \\
\text { lain (bridging) } \\
\text { X134: Kerjasama dengan teman bisnis lain (link- } \\
\text { ing) }\end{array}$ \\
\hline & $\begin{array}{l}\text { Peran } \\
\text { Pemerintah } \\
(\mathbf{X} 2)[4]\end{array}$ & $\begin{array}{l}\text { X21: Fasilitator } \\
\text { X22: Katalisator } \\
\text { X23: Regulator }\end{array}$ \\
\hline \multirow[t]{4}{*}{$\begin{array}{l}\text { Orientasi } \\
\text { Kewirausahaan } \\
(\text { OK) (Y1), [7] }\end{array}$} & $\begin{array}{l}\text { Inovatif (Y11), } \\
\text { [2] }\end{array}$ & $\begin{array}{l}\text { Y111: Kemampuan bernisiatif } \\
\text { Y112: Rajin mencari peluang atau model baru } \\
\text { Y113: Kegigihan berusaha (percistence) } \\
\text { Y114: Rasa ingin tahu tinggi }\end{array}$ \\
\hline & $\begin{array}{l}\text { Proaktif (Y12), } \\
\text { [2] }\end{array}$ & $\begin{array}{l}\text { Y121: Aktif mencari konsumen dan pasar } \\
\text { Y122: Proaktif merancang produk baru } \\
\text { Y123: Proaktif pada promosi produk } \\
\text { Y124: Proaktif menggalang dukungan pihak lain }\end{array}$ \\
\hline & $\begin{array}{l}\text { Pemecahan Ma- } \\
\text { salah (Y13), } \\
{[2]}\end{array}$ & $\begin{array}{l}\text { Y131: Assertiveness; ketegasan bertindak } \\
\text { Y132: Percaya diri } \\
\text { Y133: Perencanaan sistematik } \\
\text { Y134: Berani ambil keputusan dan risiko }\end{array}$ \\
\hline & $\begin{array}{l}\text { Kinerja Usaha } \\
\text { (Y2), [8] }\end{array}$ & $\begin{array}{l}\text { Y21: Peningkatan omzet penjualan/usaha } \\
\text { Y22: Penambahan jenis/kuantitas usaha } \\
\text { Y23: Peningkatan pendapatan usaha } \\
\text { Y24: Peningkatan keuntungan (laba) }\end{array}$ \\
\hline
\end{tabular}

\section{Hasil dan Pembahasan}

Hasil uji instrumen penelitian pada konstruk (variabel laten) orde pertama, semua nilai korelasi Product Moment di atas 0,300, artinya semua indikator valid. Sementara itu nilai Cronbach's Alpha $(\alpha)$ untuk setiap konstruk reflektif lebih besar dari 0,60, ini berarti bahwa instrumen penelitian (kuesioner) yang digunakan untuk mengukur konstruk tersebut layak dan dapat diandalkan. 
Hasil uji model pengukuran reflektif ini diperoleh setelah dilakukan pengolahan data penelitian untuk 90 responden (sampel) menggunakan alat bantu software Smart PLS 3.0, seperti tercermin pada Tabel 2 berikut,

Tabel 2. Hasil Analisis Model Pengukuran Reflektif

\begin{tabular}{|c|c|c|c|c|c|c|}
\hline Konstruk & AVE & ${ }_{(\alpha)}{ }^{\mathrm{CA}}$ & CR & $\begin{array}{l}\text { Kode } \\
\text { Item }\end{array}$ & $\begin{array}{r}\text { Out } \\
\text { er Loading }\end{array}$ & $\begin{array}{l}t \text { - Statis- } \\
\text { tic }\end{array}$ \\
\hline \multirow{4}{*}{ Rasa Percaya } & \multirow{4}{*}{$\begin{array}{c}0,544 \\
(\mathrm{p}=0.00)\end{array}$} & \multirow{4}{*}{$\begin{array}{c}0,716 \\
(\mathrm{p}=00)\end{array}$} & \multirow{4}{*}{$\begin{array}{r}0,825 \\
(\mathrm{p}=0.00)\end{array}$} & $\mathrm{X} 111$ & 0,79 & $22,19(\mathrm{~s})$ \\
\hline & & & & $\mathrm{X} 112$ & 0,72 & $12,68(\mathrm{~s})$ \\
\hline & & & & X113 & 0,59 & $8,83(\mathrm{~s})$ \\
\hline & & & & $\mathrm{X} 114$ & 0,83 & $32,09(\mathrm{~s})$ \\
\hline \multirow{4}{*}{ Norma } & \multirow{4}{*}{$\begin{array}{c}0,489 \\
(\mathrm{p}=0.00)\end{array}$} & \multirow{4}{*}{$\begin{array}{r}0,648 \\
(\mathrm{p}=0,00)\end{array}$} & \multirow{4}{*}{$\begin{array}{r}0,791 \\
(\mathrm{p}=0.00)\end{array}$} & $\mathrm{X} 121$ & 0,74 & $15,09(\mathrm{~s})$ \\
\hline & & & & $\mathrm{X} 122$ & 0,66 & $11,53(\mathrm{~s})$ \\
\hline & & & & $\mathrm{X} 123$ & 0,76 & $15,25(\mathrm{~s})$ \\
\hline & & & & $\mathrm{X} 124$ & 0,62 & $8,17(\mathrm{~s})$ \\
\hline \multirow{4}{*}{ Jaringan Kerja } & \multirow{4}{*}{$\begin{aligned} & 0,608 \\
&(\mathrm{p}=0.00)\end{aligned}$} & \multirow{4}{*}{$\begin{array}{c}0,783 \\
(\mathrm{p}=0,00)\end{array}$} & \multirow{4}{*}{$\begin{array}{r}0,861 \\
(p=0.00)\end{array}$} & $\mathrm{X} 131$ & 0,75 & $15,00(\mathrm{~s})$ \\
\hline & & & & X132 & 0,70 & $13,18(\mathrm{~s})$ \\
\hline & & & & X133 & 0,84 & $28,72(\mathrm{~s})$ \\
\hline & & & & X134 & 0,82 & $25,71(\mathrm{~s})$ \\
\hline \multirow{3}{*}{ Modal sosial } & \multirow{3}{*}{$\begin{array}{r}0,475 \\
(p=0,00)^{1}\end{array}$} & \multirow{3}{*}{$\begin{array}{r}0,897 \\
(p=0,00)\end{array}$} & \multirow{3}{*}{$\begin{array}{c}0,914 \\
(p=0,00)\end{array}$} & $X 11$ & 0,92 & $60,59(s)$ \\
\hline & & & & $X 12$ & 0,93 & $61,41(s)$ \\
\hline & & & & $X 13$ & 0,95 & $124,10(\mathrm{~s})$ \\
\hline \multirow{3}{*}{ Peran Pemerintah } & \multirow{3}{*}{$\begin{array}{r}0,712 \\
(\mathrm{p}=0.00)\end{array}$} & \multirow{3}{*}{$\begin{array}{r}0,798 \\
(\mathrm{p}=0,00)\end{array}$} & \multirow{3}{*}{$\begin{array}{r}0,881 \\
(\mathrm{p}=0.00)\end{array}$} & $\mathrm{X} 31$ & 0,83 & $25,34(\mathrm{~s})$ \\
\hline & & & & X32 & 0,89 & $32,84(\mathrm{~s})$ \\
\hline & & & & $\mathrm{X} 33$ & 0,80 & $13,35(\mathrm{~s})$ \\
\hline \multirow{4}{*}{ Inovatif } & \multirow{4}{*}{$\begin{array}{r}0,512 \\
(p=0.00)\end{array}$} & \multirow{4}{*}{$\begin{array}{c}0,781 \\
(\mathrm{p}=00)\end{array}$} & \multirow{4}{*}{$\begin{array}{r}0,807 \\
(p=0.00)\end{array}$} & Y111 & 0,74 & $14,70(\mathrm{~s})$ \\
\hline & & & & Y112 & 0,72 & $13,45(\mathrm{~s})$ \\
\hline & & & & Y113 & 0,65 & $9,77(\mathrm{~s})$ \\
\hline & & & & Y114 & 0,75 & $11,74(\mathrm{~s})$ \\
\hline \multirow{4}{*}{ Proaktif } & \multirow{4}{*}{$\begin{array}{r}0,542 \\
(p=0.00)\end{array}$} & \multirow{4}{*}{$\begin{array}{c}0,718 \\
(\mathrm{p}=00)\end{array}$} & & Y121 & 0,77 & $15,43(\mathrm{~s})$ \\
\hline & & & 0,825 & Y122 & 0,68 & $8,30(\mathrm{~s})$ \\
\hline & & & $(\mathrm{p}=0.00)$ & Y123 & 0.75 & $13,20(\mathrm{~s})$ \\
\hline & & & & Y124 & 0,75 & $13,20(\mathrm{~s})$ \\
\hline & & & & Y131 & 0,78 & $20,09(\mathrm{~s})$ \\
\hline Pemecahan Ma- & $\begin{array}{l}0,5 / 3 \\
(\mathrm{n}=0\end{array}$ & 0,751 & 0,842 & Y132 & 0,69 & $7,58(\mathrm{~s})$ \\
\hline salah & $(p=0$. & $(\mathrm{p}=00)$ & $(\mathrm{p}=0.00)$ & Y133 & 0,73 & $13,39(\mathrm{~s})$ \\
\hline & & & & Y134 & 0,80 & $14,18(\mathrm{~s})$ \\
\hline & & 0,890 & & $Y 11$ & 0,94 & $76,65(s)$ \\
\hline$O K$ & $\begin{array}{r}0,454 \\
(n-0,00)\end{array}$ & $(\mathrm{p}=0,00)$ & $\begin{array}{r}0,908 \\
(n-0,00)\end{array}$ & $Y 12$ & 0,92 & $48,20(s)$ \\
\hline & & & & $Y 13$ & 0,89 & $44,27(s)$ \\
\hline & & & & Y21 & 0,83 & $16,47(\mathrm{~s})$ \\
\hline Kinerja Usaha & 0,815 & 0,924 & 0,946 & Y22 & 0,89 & $38,53(\mathrm{~s})$ \\
\hline & $(p=0.00)$ & $(\mathrm{p}=0,00)$ & $(\mathrm{p}=0.00)$ & Y23 & 0,92 & $49,30(\mathrm{~s})$ \\
\hline & & & & Y24 & 0,96 & $149,1(\mathrm{~s})$ \\
\hline
\end{tabular}

Catatan : "s" artinya signifikan pada taraf uji 5\%, Sumber: Data Primer dianalisis (2019)

Tabel 2 memperlihatkan nilai $A V E$ dari setiap konstruk lebih dari 0,5 atau signifikan pada taraf uji statistika 5\%, hal ini berarti semua konstruk yang dipakai dalam penelitian ini mempunyai validitas dikriminan yang memadai (Hair, et al, 2017). Nilai Cronbach Alpha (CA) masing-masing konstruk lebih dari 0,6 atau signifikan pada taraf uji-t 5\% (nilai T-statistik > 1,96 atau $\mathrm{P}_{-}$Values $<0,5$ ), sehingga setiap konstruk reliabel 
pada uji nilai Cronbach Alpha 5 persen. Sedangkan nilai Composite Reliability $(C R)$ masing-masing konstruk, yang ternyata semua konstruk nilainya lebih dari 0,7 berarti juga sudah memenuhi syarat reliabilitas konstruk. Sementara itu juga semua indikator yang digunakan dalam penelitian mempunyai outer loading yang signifikan pada taraf uji_t 5 persen (nilai t_values $=1,96$ ), dimana semua indikator mempunyai nilai $T_{-}$Values lebih besar dari 1,96, seperti pada Gambar 2.

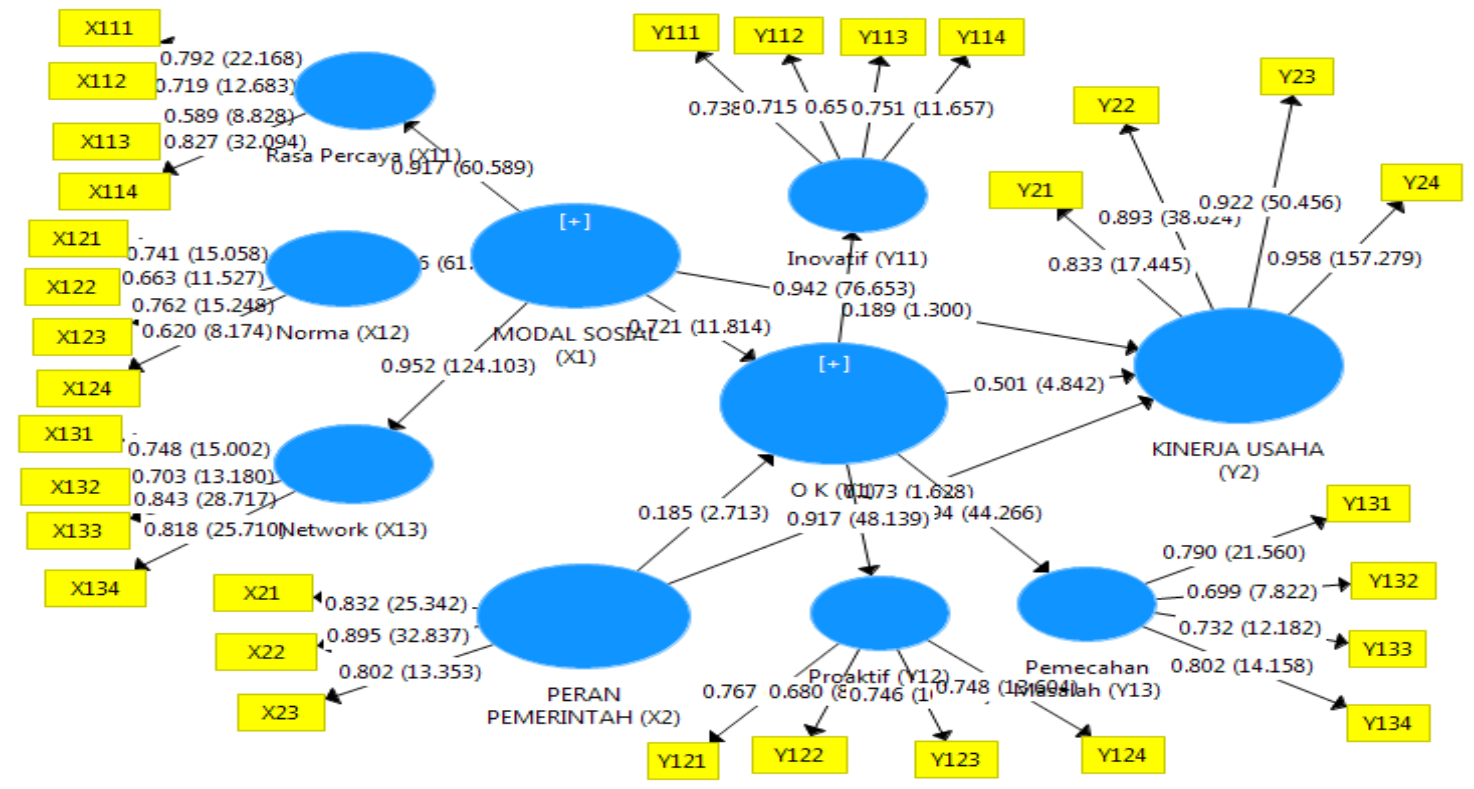

Gambar 2. Analisis Jalur (path) beserta Nilai $T_{-}$values

Oleh karena pengujian model pengukuran (outer model) semuanya sudah memenuhi syarat, berarti semua indikator dan konstruk dalam penelitian ini valid dan layak digunakan untuk analisis pada model struktural (inner model).

Model struktural dievaluasi menggunakan $R$-square untuk variabel dependen (endogen) dan nilai signifikannya di uji berdasarkan niali T-values pada setiap path (jalur). Pengujian inner model berhubungan dengan melihat hubungan antar konstruk laten dengan menganalisis hasil estimasi path coefficient dan tingkat signifikansinya. Nilai $R$ square antara 0,67 sampai 1 mengindikasikan model struktural termasuk baik, sedangkan rentang nilai $R$ square antara 0,34 sampai 0,66 mengindikasikan model struktural moderat, dan bila nilai $R$ square 0,33 ke bawah maka model struktural tergolong lemah (Christian Nitzi. 2016 ). 
Tabel 3. Nilai R Square

\begin{tabular}{lcc}
\hline $\begin{array}{c}\text { Variabel Laten } \\
\text { (Konstruk) }\end{array}$ & $\boldsymbol{R}$ Square & $\begin{array}{c}\boldsymbol{R} \text { Square } \text { Ad- } \\
\text { justed }\end{array}$ \\
\hline Kinerja Usaha & 0,655 & 0,643 \\
Orientasi Kewirausahaan & 0,754 & 0,748 \\
\hline
\end{tabular}

Sumber : Data Primer (2019), Diolah

Nilai $R$ square seperti pada Tabel 3 dapat digunakan untuk menghitung nilai $\mathrm{Q}^{2}$ atau Stone Geiser $Q$-Square test, yaitu,

$$
\mathrm{Q}^{2}=1-[(1-0,754)(1-0,655)]=1-0,085=0,915
$$

Hasil perhitungan $\mathrm{Q}^{2}$ sebesar 0,915 dikatakan mempunyai predivtive prevalence yang tinggi, sehingga model struktural yang dihasilkan sangat layak digunakan untuk memprediksi. Nilai sebesar 0,915 dapat diartikan bahwa variasi variabel laten kinerja usaha sebesar 91,5 persen mampu dijelaskan oleh variasi variabel laten modal sosial, peran pemerintah dan orientasi kewirausahaan usaha dari pengelola BUMDes di Kabupaten Jembrana, Bali, sedangkan sisanya sebesar 8,5 persen dijelaskan oleh variabel lain diluar model struktural.

Persamaan model struktural untuk estimasi konstruk endogen dapat dirumuskan sebagai berikut,

* Orientasi Kewirausahaan = 0,721 Modal Sosial + 0,185 Peran Pemerintah + Error

Kinerja Usaha = 0,189 Modal Sosial + 0,173 Peran Pemerintah + 0,501 Orientasi Kewirausahaan + Error

Analisis pengaruh langsung, pengaruh tak langsung maupun pengaruh total menggunakan koefisien semua anak panah variabel laten (Gambar 2) dengan satu ujung

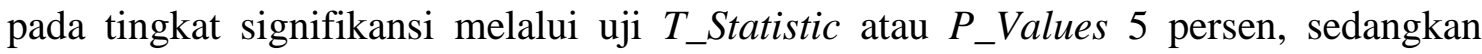
pengaruh tidak langsung ditunjukkan melalui peran satu atau beberapa variabel antara (mediasi).

Tabel 4. Nilai Path Coefficient

\begin{tabular}{lllllc}
\hline \multicolumn{1}{c}{ Hubungan } & $\begin{array}{l}\text { Original } \\
\text { Sample }\end{array}$ & $\begin{array}{l}\text { Standard } \\
\text { Deviasi }\end{array}$ & T_Statc & $\boldsymbol{P} \_$Val & Hasil \\
\hline $\mathrm{X}_{1}(\mathrm{MS}) \rightarrow \mathrm{Y}_{2}(\mathrm{KU})$ & 0,189 & 0,146 & 1,300 & 0,194 & Tidak Signifikan \\
$\mathrm{X}_{2}(\mathrm{PP}) \rightarrow \mathrm{Y}_{2}(\mathrm{KU})$ & 0,173 & 0,106 & 1,628 & 0,104 & Tidak Signifikan \\
$\mathrm{Y}_{1}(\mathrm{OK}) \rightarrow \mathrm{Y}_{2}(\mathrm{KU})$ & 0,501 & 0,103 & 4,842 & 0,000 & Signifikan \\
$\mathrm{X}_{1}(\mathrm{MS}) \rightarrow \mathrm{Y}_{1}(\mathrm{OK})$ & 0,721 & 0,061 & 11,814 & 0,000 & Signifikan \\
$\mathrm{X}_{2}(\mathrm{PP}) \rightarrow \mathrm{Y}_{1}(\mathrm{OK})$ & 0,185 & 0,068 & 2,713 & 0,007 & Signifikan \\
\hline
\end{tabular}

Sumber : Data Primer (2019), Diolah

Tabel 4 menjelaskan pengaruh langsung dari konstruk modal sosial (MS) berpengaruh positif dan tidak signifikan terhadap kinerja usaha $(\mathrm{KU})$, tetapi signifikan terhadap orientasi kewirausahaan (OK). Selanjutnya konstruk peran pemerintah (PP) berpengaruh positif dan tidak signifikan terhadap kinerja usaha (KU), tetapi signifikan 
terhadap orientasi kewirausahaan (OK). (KU). Terakhir konstruk orientasi kewirausahaan (OK) berpengaruh positif dan signifikan terhadap kinerja usaha (KU).

Tabel 5. Nilai Indirect Effect

\begin{tabular}{llllll}
\hline Hubungan & $\begin{array}{l}\text { Original } \\
\text { Sample }\end{array}$ & $\begin{array}{l}\text { Standard } \\
\text { Deviasi }\end{array}$ & $\begin{array}{r}\text { Ttatistics } \\
\text { Values }\end{array}$ & Hasil \\
\hline $\left.\mathrm{X}_{1}(\mathrm{MS}) \underset{\mathrm{Y}}{\mathrm{M}} \rightarrow \mathrm{KU}\right)$ & 0,361 & 0,081 & 4,433 & 0,000 & Signifikan \\
$\begin{array}{l}\text { Melalui } \mathrm{Y}_{1}(\mathrm{OK}) \\
\mathrm{X}_{2}(\mathrm{PP})\end{array} \mathrm{Y}_{2}(\mathrm{KU})$ & 0,093 & 0,309 & 2,351 & 0,019 & Signifikan \\
Melalui $\left.\mathrm{Y}_{1}(\mathrm{OK})\right)$ & & & & & \\
\hline
\end{tabular}

Sumber : Data Primer (2019), Diolah.

Tabel 5 menunjukkan bahwa konstruk eksogen modal sosial (MS) melalui mediasi orientasi kewirausahaan (OK) berpengaruh tidak langsung secara positif dan signifikan terhadap kinerja usaha (KU)). Demikian pula konstruk eksogen peran pemerintah (PP) melalui mediasi orientasi kewirausahaan (OK) berpengaruh positif dan signifikan terhadap kinerja usaha $(\mathrm{KU})$.

Tabel 6. Nilai Total Effects

\begin{tabular}{lllclll}
\hline Hubungan & $\begin{array}{l}\text { Original } \\
\text { Sample }\end{array}$ & $\begin{array}{l}\text { Standard } \\
\text { Deviasi }\end{array}$ & $\begin{array}{c}\text { T } \\
\text { Statis- } \\
\text { tics }\end{array}$ & Values & Hasil & Keterangan \\
\hline $\mathrm{X}_{1}(\mathrm{MS}) \rightarrow$ & 0,550 & 0,129 & 4,265 & 0,000 & $\begin{array}{l}\text { Signif- } \\
\text { ikan }\end{array}$ & $\begin{array}{l}\text { Mediasi } \\
\text { Penuh }\end{array}$ \\
$\mathrm{X}_{2}(\mathrm{KU})$ & & & & & $\begin{array}{l}\text { Signif- } \\
\text { ikan }\end{array}$ & $\begin{array}{l}\text { Mediasi } \\
\text { Penuh }\end{array}$ \\
$\mathrm{X}_{2}(\mathrm{OK}) \rightarrow$ & 0,266 & 0,107 & 2,482 & 0,013 & \\
$\mathrm{Y}_{2}(\mathrm{KU})$ & & & & & & \\
\hline
\end{tabular}

Sumber : Data Primer (2019), Diolah

Tabel 6 menunjukkan pengaruh total antar konstruk dalam model struktural semuanya signifikan pada taraf uji 5\%. Secara umum konstruk eksogen modal sosial (MS) dan peran pemerintah (PP) berpengaruh positif dan signifikan terhadap konstruk endogen kinerja usaha $(\mathrm{KU})$. Oleh karena pengaruh langsung konstruk modal sosial (MS) tidak signifikan tetapi pengaruh tidak langsung yang signifikan terhadap kinerja usaha (KU), maka terjadi mediasi penuh (full mediation) oleh konstruk orientasi kewirausahaan (OK). Demikian juga pada konstruk peran pemerintah (PP) terjadi mediasi penuh (full mediation) oleh konstruk orientasi kewirausahaan (OK) terhadap kinerja usaha (KU), karena ada pengaruh langsung yang tidak signifikan tetapi signifikan pada pengaruh tidak langsung.

\section{Kesimpulan dan Saran \\ 4.1 Kesimpulan}

1) Model pengukuran yang diperoleh valid dan layak, sedangkan model struktural baik dengan $\mathrm{Q}^{2}$ (Stone Geiser Q-Square) yaitu 0,915, yang berarti model memiliki prevalensi prediksi yang tinggi. sehingga model struktural yang dihasilkan sangat 
layak digunakan untuk memprediksi. Model persamaan struktural yang diperoleh adalah,

Orientasi Kewirausahaan $=0,721$ Modal Sosial + 0,185 Peran Pemerintah +

$$
\text { Error }
$$

Kinerja Usaha $=0,189$ Modal Sosial + 0,173 Peran Pemerintah + 0,501 Orientasi Kewirausahaan + Error

2) Sesuai dengan konsep dan fakta empiris peran pemerintah dan modal sosial secara langsung masing-masing berpengaruh positif dan signifikan terhadap orientasi kewirausahaan pengelola BUMDes. Dilain pihak, modal sosial dan peran pemerintah secara langsung belum signifikan meningkatkan kinerja usaha BUMDes, akan tetapi oreintasi kewirausahaan pengelola BUMDes berpengaruh cukup positif dan signifikan terhadap kinerja usaha BUMDes di Kabupaten Jembrana, Bali.

3) Secara total modal sosial memiliki pengaruh positif dan signifikan terhadap kinerja usaha BUMDes yang sepenuhnya dimediasi oleh orientasi kewirausahaan pengelola BUMDes. Begitu juga. secara total peran pemerintah memiliki dampak positif dan signifikan terhadap kinerja usaha yang sepenuhnya dimediasi oleh orientasi kewirausahaan pengelola BUMDes di Kabupaten Jembrana, Bali.

\subsection{Saran (Rekomendasi)}

1) Kapasitas modal sosial pelaku usaha pariwisata di Kabupaten Jembrana sebenarnya tinggi, sehingga hal ini perlu diberdayakan agar dapat berperan dalam meningkatkan budaya wirausaha dan kinerja usaha BUMDes di Kabupaten Jembrana, Bali.

2) Peran pemerintah daerah khususnya Dinas Pemberdayaan Masyarakat (PMD) Kabupaten Jembrana perlu ditingkatkan terus menerus melalui fasilitas pelatihan pada pengelola dan pemodalan BUMDes untuk meningkatkan budaya wirausaha pengelola BUMDes di Kabupaten Jembrana, Bali

\section{Ucapan Terima Kasih}

Terima kasih disampaikan kepada Universitas Udayana, khususnya kepada Lembaga Penelitian dan Pengabdian kepada Masyarakat dan Fakultas Matematika dan Ilmu Pengetahuan Alam yang membiayai penelitian ini berdasarkan Surat Perjanjian Penugasan Pelaksanaan Penelitian Unggulan Program Studi (PUPS) pada tahun anggaran 2019, No.2000 / UN14.2.8.II / LT / 2019, tanggal 10 April 2019. 


\section{Daftar Pustaka}

[1] Christian Nitzi. 2016. The use of partial least squares structural equation modelling (PLS-SEM) in management accounting research: Directions for future theory devel opment. Journal of Accounting Literature; 37:19-35 (DOI: 10.2139/ssrn.2469802).

[2] Fukuyama. 2000. Social Capital and Civil Society. Institute of Public Policy. George Mason University. (DOI : 10.5089/9781451849585.001)

[3] Gandhiadi G K, Sudibia K, Suyana Utama M, Saskara I A N. 2017. The Influence of Social Capital on Subjective Wellbeing: A Structural Model for The Weaving Industry in Bali Province of Indonesia. International Journal of Economics, Commerce \& Management (IJECM), Volume 5(6);pp 216-230. United Kingdom. ISSN 2348-0386. (DOI : http://ijecm.co.uk/wp-content/uploads/2017/06/5614.pdf)

[4] Hair, J.F., Hult, G.T., Ringle, C.M. \& Sarstedt, M. 2017. A primer on partial least squares structural equation modeling (PLS-SEM). Second edition. Los Angeles : SAGE Publications, Inc. ISBN 9781483377445. (http://lccn.loc.gov/2016005380)

[5] Hamed Taherdoost. 2016. Validity and Reliability of the Research Instrument; How to Test the Validation of a Questionnaire/Survey in a Research. International Journal of Academic Research in Management (IJARM), Vol. 5, No. 3, pp: 28-36, ISSN: 2296-1747 (DOI: 10.2139/ssrn.3205040)

[6] Suci, R.P. 2009. Peningkatan Kinerja Melalui Orientasi Kewirausahaan, Kemampuan Manajemen, dan Strategi Bisnis (Studi Kasus pada Industri Kecil Menengah Bordir di Jawa Tengah). Jurnal Manajemen dan Kweirausahaan. Vol 11, No.1. Hal 46-58 (DOI : https://doi.org/10.9744/jmk.11.1.pp.46-58)

[7] Taranggana Gani Putra. 2017. Peran Pemerintah Daerah Dan Partisipasi Pelaku Usaha Dalam Pengembangan UMKM Manik-Manik Kaca di Kabupaten Jombang. Kebijakan dan Manajemen Publik; 3:1, ISSN 2303 - 3413 